\title{
BMJ Open Improving the management of pain from advanced cancer in the community: study protocol for a pragmatic multicentre randomised controlled trial
}

\author{
Matthew J Allsop, ${ }^{1}$ Alexandra Wright-Hughes, ${ }^{2}$ Kath Black, ${ }^{1,3}$ Suzanne Hartley, ${ }^{2}$ \\ Marie Fletcher, ${ }^{2}$ Lucy E Ziegler, ${ }^{1}$ Bridgette M Bewick, ${ }^{4}$ David Meads, ${ }^{5}$ \\ Nicholas D Hughes, ${ }^{6} \mathrm{~S}$ José Closs, ${ }^{6}$ Claire Hulme, ${ }^{5}$ Sally Taylor, ${ }^{1}$ Kate Flemming, ${ }^{7}$ \\ Julia Hackett, ${ }^{1}$ John L O'Dwyer, ${ }^{5}$ Julia M Brown, ${ }^{2}$ Michael I Bennett ${ }^{1}$
}

To cite: Allsop MJ, WrightHughes A, Black K, et al. Improving the management of pain from advanced cancer in the community: study protocol for a pragmatic multicentre randomised controlled trial. BMJ Open 2018;8:e021965. doi:10.1136/ bmjopen-2018-021965

- Prepublication history and additional material for this paper are available online. To view these files, please visit the journal online (http://dx.doi. org/10.1136/bmjopen-2017021965).

\section{MJA and AW-H contributed} equally.

Received 29 January 2018 Revised 22 February 2018 Accepted 28 February 2018

Check for updates

For numbered affiliations see end of article.

Correspondence to Dr Matthew J Allsop; m.j.allsop@leeds.ac.uk

\section{ABSTRACT}

Introduction For patients with advanced cancer, research shows that pain is frequent, burdensome and undertreated. Evidence-based approaches to support cancer pain management have been developed but have not been implemented within the context of the UK National Health Service. This protocol is for a pragmatic multicentre randomised controlled trial (RCT) to assess feasibility, acceptability, effectiveness and costeffectiveness for a multicomponent intervention for pain management in patients with advanced cancer. Methods and analysis This trial will assess the feasibility of implementation and uptake of evidencebased interventions, developed and piloted as part of the Improving the Management of Pain from Advanced Cancer in the Community Programme grant, into routine clinical practice and determine whether there are potential differences with respect to patient-rated pain, patient pain knowledge and experience, healthcare use, quality of life and cost-effectiveness. 160 patients will receive either the intervention (usual care plus supported self-management) delivered within the oncology clinic and palliative care services by locally assigned community palliative care nurses, consisting of a self-management educational intervention and eHealth intervention for routine pain assessment and monitoring; or usual care. The primary outcomes are to assess implementation and uptake of the interventions, and differences in terms of pain severity. Secondary outcomes include pain interference, participant pain knowledge and experience, and cost-effectiveness. Outcome assessment will be blinded and patient-reported outcome measures collected via post at 6 and 12 weeks following randomisation.

Ethics and dissemination This RCT has the potential to significantly influence National Health Service delivery to community-based patients with pain from advanced cancer. We aim to provide definitive evidence of whether two simple interventions delivered by community palliative care nurse in palliative care that support-self-management are clinically effective and cost-effective additions to standard community palliative care.

Trial registration number ISRCTN18281271; Pre-results.

\section{Strengths and limitations of this study}

- This is the first randomised controlled trial to examine the effect of a multicomponent complex intervention comprising evidence-based approaches to pain management in patients with advanced cancer.

- To optimise the generalisability of the findings, this multicentre trial will include patients from palliative care services across the UK.

- This trial includes objectives that assess changes in pain knowledge and experience as well as pain intensity outcomes.

- The pragmatic approach adopted by this trial will enable identification of issues arising from the implementation of a complex intervention in palliative care services at transitions between secondary and community care in the UK.

- A limitation is that the pragmatic approach may have an impact on fidelity to the interventions; steps have been taken to avoid and monitor contamination and measure adherence to interventions.

\section{INTRODUCTION}

Each year in the UK, 163000 people die from cancer. ${ }^{1}$ For patients with cancer, research shows that pain is frequent, burdensome and undertreated. $^{2-5}$ Over two-thirds $(66.4 \%)$ of these patients will experience pain during advanced, metastatic or terminal stages of their cancer. ${ }^{5}$ Many patients with cancer spend their last 6 months of life living in the community, typically at home, though many are admitted as inpatients nearer to death. ${ }^{6}$ Barriers to good pain control include inadequate support and patient education, ${ }^{7}$ poor assessment and communication, ${ }^{8}$ and lack of access to an adequate prescription and timely analgesia. ${ }^{9}$ A range of approaches have been developed that seek to improve the management of pain in patients with advanced cancer but have not been implemented within the 
context of the National Health Service (NHS) in the UK. Three emerging approaches that address key barriers to pain management for patients with advanced cancer are outlined, including referral to specialist palliative care, self-management of pain and analgesia, and routine monitoring of pain.

\section{Specialist palliative care}

Specialist palliative care aims to relieve suffering and improve quality of life for people with advanced diseases, such as cancer, who are facing death. For patients with advanced cancer, several randomised controlled trials (RCTs) $)^{10-14}$ have shown that early access to palliative care can improve symptoms, reduce acute hospital admissions, minimise aggressive cancer treatments and enable patients to make choices about their end-of-life care, including exercising the choice to die at home. Interventions in these trials varied, but common characteristics included assessment and several follow-up consultations by specialist palliative care teams over a period of $2-3$ months. Where reported, patients were recruited and received these interventions about 6 to 14 months before their death. ${ }^{10-14}$ Collectively, these data suggest that a dose of three to four palliative care contacts applied about 6 months before death is associated with better end-of-life care. The trials from which this evidence is derived were based in North America, and the studies vary widely in their definition of what constitutes palliative care services and who provides them. These limitations have prevented direct translation and implementation of this evidence within the context of the UK NHS.

\section{Supporting self-management of pain and analgesia}

Pain for patients with advanced cancer is a complex and dynamic experience. ${ }^{15}$ Poor knowledge and fearful attitudes within patients towards cancer pain and analgesia are associated with reluctance to commence opioids, reduced medication adherence and higher pain intensity. ${ }^{16} 17$ Providing information to patients with cancer pain and addressing concerns regarding pain and analgesia are effective interventions that support self-management and lead to improvements in pain outcomes. ${ }^{18-22}$ While evidence supports the use of self-management approaches, there remains uncertainty on the optimum dose and components of a self-management intervention, and how best to implement these in routine practice.

\section{Routine monitoring of pain}

Assessing pain and presenting data to physicians prior to consultation, who then use it within discussions, significantly improves pain outcomes and quality of life for patients. ${ }^{23}$ Assessment alone without ensuring that this is seen by prescribing clinicians does not lead to improvements in pain, ${ }^{24}$ highlighting the need for interventions to alert clinicians to patients' symptoms. Two large RCTs, one conducted in the USA ${ }^{25}$ and one in the Netherlands, ${ }^{26}$ have demonstrated improvements in cancer pain when combinations of interventions have been evaluated. The first compared telephone self-management support from nurses combined with automated symptom monitoring, with usual care. Significant reductions in pain scores were demonstrated over a 12-month period. ${ }^{25}$ The second combined specialist pain consultation with nurse-led self-management support and compared this with usual care. ${ }^{26}$ Over an 8-week follow-up period, significant benefits were experienced by intervention patients in pain scores and reduction in interference in daily living from pain. Similar to education self-management approaches, there is uncertainty about the optimum dose, alongside a lack of evidence of implementation in the context of the UK NHS.

\section{Rationale}

We have developed a complex intervention consisting of three distinct components: (1) referral to community palliative care support, (2) a resource to support self-management of pain and analgesia, and (3) an electronic pain monitoring system. We hypothesise that within oncology (or related) services, screening and referral of community-based patients with pain from advanced cancer to a cancer pain pathway, combined with a package of routine pain assessment and monitoring using an e-health tool, will reduce the extent of pain and psychological distress reported by the patient.

We will undertake a multicentre RCT to assess the acceptability and feasibility of implementation of the complex intervention, its potential cost-effectiveness and impact on pain management.

\section{METHODS AND ANALYSIS}

This trial is the fourth and final project of a National Institute for Health Research Programme Grant for Applied Research (NIHR PGfAR), which consists of interlinked studies aiming to improve the management of pain from advanced cancer in the community: Improving the Management of Pain from Advanced Cancer in the CommuniTy (IMPACCT).

The programme follows the Medical Research Council Framework guidance for the design and evaluation of complex interventions ${ }^{27}$ and consists of the following component projects:

- To design and test a cancer pain pathway that allows early intervention and promotes self-management.

- To demonstrate the feasibility of routine cancer pain monitoring within the NHS.

- To promote non-medical prescribing and develop the role of community pharmacists.

- To establish the feasibility of delivery of our intervention in routine care, and potential effectiveness on patient outcomes and cost-effectiveness (which this protocol relates to).

\section{Aims}

The trial aims to assess the feasibility of implementation and uptake of evidence-based interventions, developed 


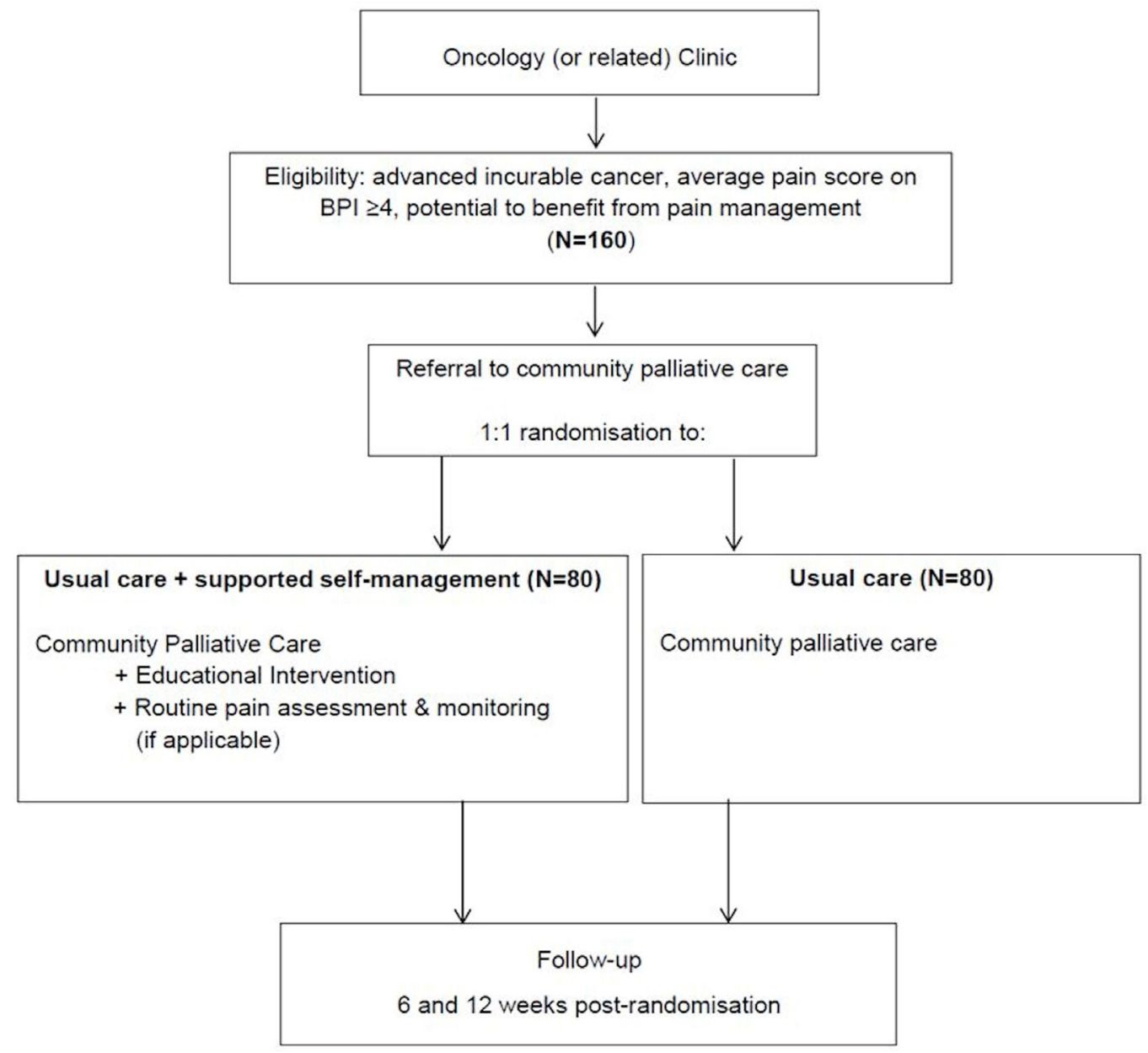

Figure 1 Trial flow diagram.

and piloted as part of the IMPACCT NIHR PGfAR, into routine clinical practice and determine whether there are potential differences with respect to (1) patient-rated pain, (2) patient pain knowledge and experience, (3) healthcare use, (4) quality of life and (5) cost-effectiveness.

Our intervention, combining usual care and supported self-management, including an educational resource and pain monitoring, aims:

- To improve the management of cancer pain for palliative care patients who are living at home.

- To enable patients to more easily access support and advice, communicate their pain, and obtain timely and effective medication.

- To educate patients on tackling cancer pain through an educational intervention.

\section{Design}

This is a pragmatic multicentre RCT to evaluate the feasibility of delivery and implementation of a supported self-management intervention into routine clinical practice in the UK for patients with cancer, which is active and incurable; and its potential impact on pain management and cost-effectiveness (see figure 1 for a trial flow diagram). Qualitative and cost-effectiveness components are embedded.
We will aim to recruit 160 participants at the point of identification for referral into palliative care and follow-up at 6 and 12 weeks. Participants will be randomised on a 1:1 basis to receive either usual care plus supported self-management, delivered within the oncology clinic and palliative care services by locally assigned community palliative care nurses, or usual care. As part of usual care, all participants will be referred to their local palliative care team for pain management.

\section{Objectives}

Objectives relate to both the feasibility of delivery and implementation of interventions into routine practice and an assessment of the effectiveness of the intervention:

- Delivery and implementation of the intervention: The primary implementation objective is to evaluate adherence in terms of the uptake and retention rate of each intervention through process evaluation, including qualitative study.

- Potential effectiveness of the intervention: The primary effectiveness objective is to assess the effectiveness of the intervention compared with usual care as measured by pain severity on the Brief Pain Inventory (BPI) 12 weeks after randomisation. Secondary objectives will assess differences at 6 weeks, 


\begin{tabular}{|c|c|}
\hline $\begin{array}{l}\text { Eligibility } \\
\text { criteria }\end{array}$ & Details \\
\hline Inclusion criteria & $\begin{array}{l}\text { 1. Male or female aged } \geq 16 \text { years } \\
\text { 2. Diagnosis of advanced incurable } \\
\text { cancer (locally advanced or metastatic) } \\
\text { Experiencing cancer-related pain (tumour } \\
\text { or treatment related) with a pain score } \\
\text { of } \geq 4 \text { on the 'average pain' item of the } \\
\text { Brief Pain Inventory } \\
\text { 3. Has the potential to benefit from pain } \\
\text { management } \\
\text { 4. Expected prognosis of } \geq 12 \text { weeks } \\
\text { 5. Living at home } \\
6 \text {. The patient is living in the local } \\
\text { catchment area for a participating } \\
\text { hospice } \\
\text { 7. The patient is able and willing to } \\
\text { provide written informed consent }\end{array}$ \\
\hline Exclusion criteria & $\begin{array}{l}\text { 1. Patients who are currently receiving } \\
\text { or have previously received community } \\
\text { palliative care support } \\
\text { 2. The patient has insufficient literacy, or } \\
\text { proficiency in English to contribute to the } \\
\text { data collection required for the research } \\
\text { 3. Patients will be excluded if they lack } \\
\text { capacity to provide informed consent to } \\
\text { this trial } \\
\text { 4. Patients with dominant chronic pain } \\
\text { that is not cancer related (tumour or } \\
\text { treatment) }\end{array}$ \\
\hline
\end{tabular}

patient-rated pain on the 7-point global rating of change in pain, ${ }^{28}$ healthcare use in each arm, patient's pain knowledge and experience, patient's general and cancer-specific quality of life, and cost-effectiveness of the interventions.

\section{Recruitment, setting and participants}

Participants will be identified and recruited in the oncology (or related) clinic by the research nurse, in consultation with the patient's clinician/treating team. Prior to the start of recruitment into the trial, research centres will be required to have obtained local ethical and management approvals and undertaken training in the intervention and in the trial procedures delivered by the central trial team.

To be included in the trial, participants are required to meet the eligibility criteria described in table 1 .

All patients presenting to clinics with a cancer diagnosis of advanced incurable disease will be screened. Data will be recorded anonymously to document reasons for ineligibility or decline in participation to monitor trial uptake and recruitment progress, and representativeness of the trial population.

Patients meeting the eligibility criteria will be approached by the research nurse while they attend the clinic for their standard follow-up care to confirm eligibility and provide verbal and written details about the trial. Patients will be provided with a Participant Information Sheet and given as long as they need to consider participation in the trial, as well as the opportunity to discuss the trial with their family and other healthcare professionals. Patients will then be asked whether they would be willing to take part in the trial and informed consent, and baseline assessments, will be obtained in a location convenient for the participant, at their home or clinic.

\section{Randomisation and blinding}

Following confirmation of eligibility, written informed consent and completion of baseline assessments, participants will be randomised into the trial by the research nurse. Randomisation will be performed centrally via an automated system at the Clinical Trials Research Unit at the University of Leeds. Participants will be randomised on a 1:1 basis to receive either usual care plus supported self-management or usual care, using a computer-generated minimisation programme, incorporating a random element, to ensure treatment groups are well balanced for the following: average pain at baseline on the BPI (4-6, 7-10) and recruiting site. The recruiting team are not involved in subsequent intervention delivery.

\section{Intervention}

Both usual care, and the intervention, usual care plus supported self-management will be delivered within the oncology clinic and palliative care services by locally assigned community palliative care nurses. As part of usual care, all participants will be referred to their local palliative care team for pain management. Supported self-management will consist of an educational intervention 'Tackling Cancer Pain' and an e-Health routine pain assessment and monitoring intervention 'Pain Check'. Components of the trial intervention are detailed in table 2 .

\section{Intervention delivery}

Training in the use of the interventions will be provided to the Community Palliative Care Team prior to the participating centres opening to recruitment. Training will be provided by the trial researchers based at the University of Leeds and involved in the IMPACCT Programme Grant working closely with the lead nurse at palliative care sites, recruiting sites and the administrative support staff for the community team. As part of the training, the Community Palliative Care Team will receive instructions for training the participants in the interventions, which will include a demonstration for the participant on how to log on and use PainCheck at the initial visit, and written instructions and a contact for any future queries will be provided. The participants will receive the educational intervention 'Tackling Cancer Pain' booklet and DVD from the palliative care team and asked to use it as much and as often as they would like. 


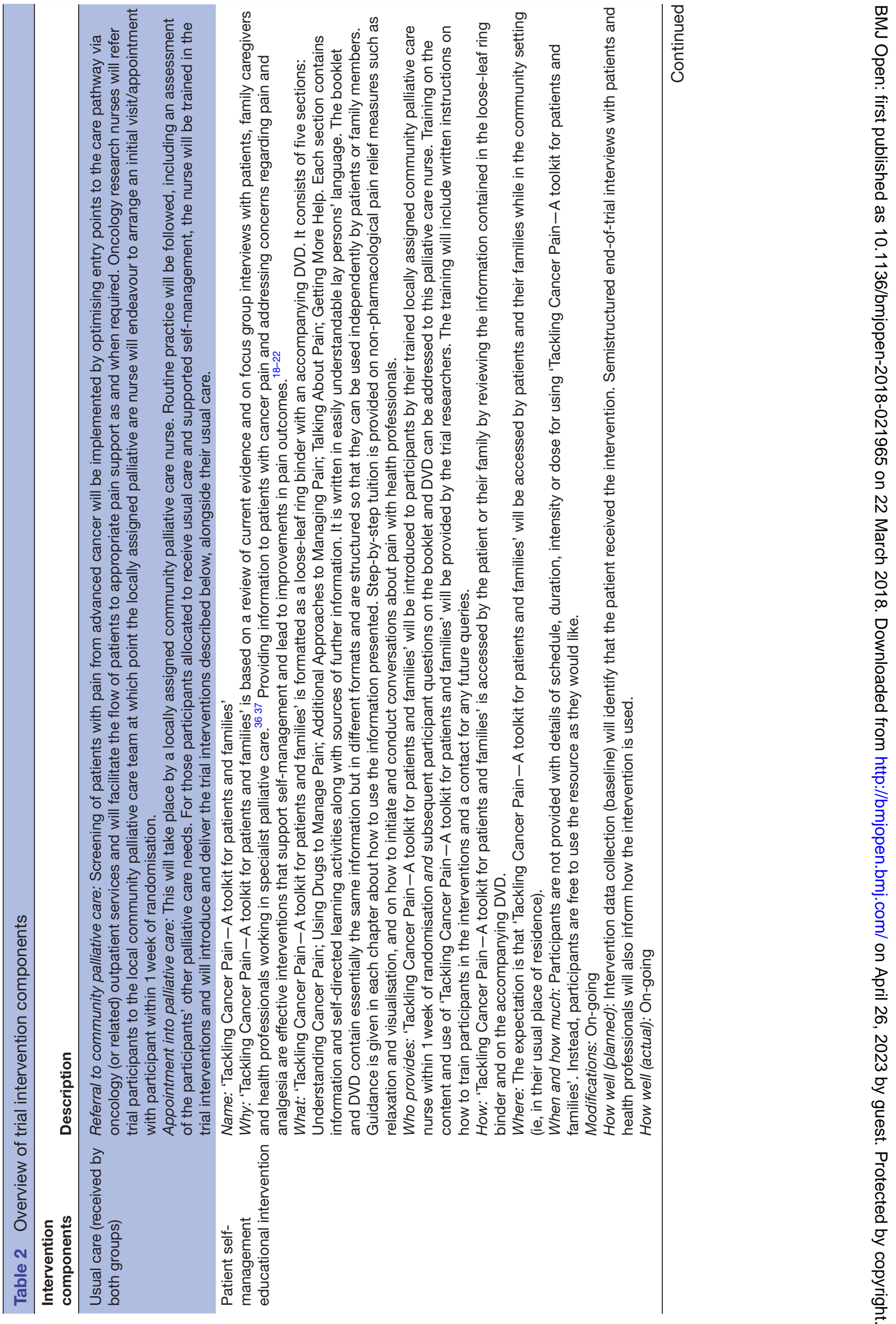


Measuring adherence to the interventions

We will record steps taken to ensure consistency in the delivery of the interventions-including training sessions with palliative care nurses such as additional training on delivery of the routine pain assessment and monitoring intervention for new staff. Monitoring adherence to the educational and routine pain assessment and monitoring interventions will involve the participants, the locally assigned community palliative care nurse and information directly from the routine pain assessment and monitoring tool.

\section{Contamination}

The risk of contamination between the two trial arms will be minimal as the educational intervention and routine pain monitoring will be made available only to participants allocated to the supported self-management arm of the trial, and there is little opportunity for participants in either trial arms to meet and discuss treatment. The importance of contamination was included in site training, so site teams are made aware not to share materials. We will record the number of contacts in community palliative care and the staff involved in the care to explore the potential for contamination. The number of Tackling Cancer Pain booklets and accompanying DVDs provided to each hospice will be monitored against the number of participants allocated to receive this intervention to ensure these are not being used for other patients. The online pain monitoring system can only be used by participants allocated to the intervention who are assigned a trial specific username and password obtained from the research team. There is no risk of contamination in the recruiting clinics as intervention delivery takes place in the community palliative care setting; notification of trial referrals to the palliative care team will clearly document the participants' randomisation allocation. We will monitor the timing at which patients are referred into palliative care and documentation of previous palliative care discussions.

\section{Assessments and data collection}

Required data, assessment tools, collection time points and processes are summarised in table 3 and detailed further in online supplementary appendix 1 .

\section{Clinical data}

Clinical follow-up data will be obtained directly from participant's hospital and palliative care records by the research nurse and palliative care team up to 12 weeks post-randomisation. Data recorded will include healthcare use, including referral and contacts with community palliative care, hospital attendances and admissions, prescription medication use and use of pain relief, and related unexpected serious adverse events. All-cause mortality will be collected continuously throughout the trial up until the point of the final participant's 12-week follow-up assessment. Details of participants and health professional's use of PainCheck will be obtained directly from the PainCheck system via an export into Microsoft Excel in comma separated values (CSV) format.

\section{Participant-completed data}

Patient-reported outcome measures are collected via post at 6 and 12 weeks following randomisation. Where required, the trial researcher will collect this data by telephone.

Participant questionnaires are posted at weeks 5 and 11 for each follow-up time point, following which the trial researcher will contact the participant by telephone to check receipt and offer completion of the questionnaires over the phone if the participant wishes to do so. If the questionnaire pack is not completed over the phone, and questionnaires are not returned by post 1 week later, the trial researcher will telephone the participant again to remind them. If contact cannot be made, the trial researcher will continue to attempt to contact the participants up to weeks 8 and 14 for each follow-up time point. If the trial researcher becomes unblinded to treatment allocation, this will be recorded and the subsequent follow-up telephone call at 12 weeks will be conducted by an alternative researcher.

Prior to contacting the participant for the follow-up visits or to post the questionnaires, the participants' survival status will be established by the central research team via the general practitioner or the oncology research nurse.

At the end of the 12-week follow-up period, participants will receive a thank you letter through the post (along with their 12-week questionnaires).

\section{Qualitative interviews}

A subsample of 15 consenting usual care plus supported self-management arm participants will be invited to take part in a semistructured interview at approximately 6 or 12 weeks post-randomisation. The interview will explore what participants felt about referral to community palliative care, how they used the Tackling Cancer Pain booklet/DVD and PainCheck, and if they found the interventions useful. A proportion of participants will be interviewed at 6 weeks to ensure a representative sample considering loss to follow-up for illness or death by 12 weeks. Participants will be selected based on their age, gender, community palliative care team (hospice) and level of PainCheck use.

A sample of 15 palliative care nurses will be invited to take part in a semistructured end-of-trial interview in order to explore their thoughts on the interventions, if they found the interventions useful, how the interventions impacted on pain management and their clinical practice, and potential within-trial contamination. Nurses will be asked to sign a consent form before the interview begins and will be selected based on their team (hospice), level of PainCheck use and the number of trial participants they have seen.

Both interviews will be conducted by a different trial researcher to that involved in other data collection, will last approximately $60 \mathrm{~min}$ and will be audio-recorded and transcribed verbatim. 
Table 3 Summary of assessment type, completers and timing

\begin{tabular}{|c|c|c|c|c|c|}
\hline \multirow[b]{2}{*}{ Assessment } & \multirow{2}{*}{$\begin{array}{l}\text { Who to complete/ } \\
\text { action }\end{array}$} & \multicolumn{4}{|c|}{ Timeline (weeks post-randomisation) } \\
\hline & & Screening & Baseline & Week 6 & Week 12 \\
\hline \multicolumn{6}{|l|}{ Baseline data (collected from case notes) } \\
\hline $\begin{array}{l}\text { Demographic data, eligibility, written informed } \\
\text { consent }\end{array}$ & Research nurse & $x$ & & & \\
\hline Background and medical history & Research nurse & & $\mathrm{x}$ & & \\
\hline $\begin{array}{l}\text { Referral to local participating community palliative } \\
\text { care team }\end{array}$ & Research nurse & & $\mathrm{x}$ & & \\
\hline $\begin{array}{l}\text { Schedule initial appointment within } 1 \text { week; deliver } \\
\text { usual care OR usual care and introduction of trial } \\
\text { interventions as determined by randomisation } \\
\text { allocation }\end{array}$ & Palliative care team & & $\mathrm{x}$ & & \\
\hline \multicolumn{6}{|c|}{ Clinical follow-up data (collected from case notes or hospice system for example, SystmOne) } \\
\hline Use of Intervention and usual care details & Palliative care team & & & & $\mathrm{x}$ \\
\hline All-cause mortality & Palliative care team & & & & $\mathrm{x}$ \\
\hline Serious adverse event reporting & Palliative care team & & Ongoing $r$ & porting & \\
\hline \multicolumn{6}{|c|}{ Clinical follow-up data (collected from case notes, hospital system for example, SystmOne and PPM database) } \\
\hline Healthcare use & Research nurse & & & & $\mathrm{x}$ \\
\hline Pain medication & Research nurse & & & $\mathrm{x}$ & $\mathrm{x}$ \\
\hline $\begin{array}{l}\text { Date of referral to community palliative care, } \\
\text { no and details of contacts }\end{array}$ & Research nurse & & & & $\mathrm{x}$ \\
\hline All-cause mortality & Research nurse & & & & $\mathrm{x}$ \\
\hline Serious adverse event reporting & Research nurse & & Ongoing $r$ & jorting & \\
\hline \multicolumn{6}{|c|}{ Patient-completed questionnaires (completed in clinic at baseline and at home/overtelephone for follow-up visits) } \\
\hline $\mathrm{BPI}$ assessment & Trial researcher & & $\mathrm{x}$ & $x$ & $\mathrm{x}$ \\
\hline 7-point global rating change of pain & Trial researcher & & & $\mathrm{x}$ & $\mathrm{x}$ \\
\hline Healthcare use (Health Economics questionnaire) & Trial researcher & & $x$ & $x$ & $x$ \\
\hline Patient Pain Questionnaire ${ }^{40}$ & Trial researcher & & $\mathrm{X}$ & $\mathrm{x}$ & $\mathrm{x}$ \\
\hline$E Q-5 D^{41}$ & Trial researcher & & $\mathrm{x}$ & $x$ & $x$ \\
\hline EORTC QLQ-C30 ${ }^{42}$ & Trial researcher & & $\mathrm{X}$ & $\mathrm{x}$ & $\mathrm{x}$ \\
\hline \multicolumn{6}{|l|}{ Clinical follow-up data (collected via GP practice) } \\
\hline Date of referral to community palliative care & Trial researcher & & Ongoing $r \in$ & porting & \\
\hline Survival status & $\begin{array}{l}\text { Trial researcher/Leeds } \\
\text { Institute of Clinical } \\
\text { Trials Research }\end{array}$ & & Ongoing $r$ & porting & \\
\hline \multicolumn{6}{|l|}{ Routine monitoring data } \\
\hline $\begin{array}{l}\text { Uptake (patients and palliative care nurse) and } \\
\text { patient-reported pain diaries }\end{array}$ & Trial researcher ${ }^{*}$ & & Ongoing $r \epsilon$ & oorting & \\
\hline Qualitative participant interviews & Trial researcher ${ }^{\star}$ & & $\begin{array}{l}\sim 6 \text { or } 12 \mathrm{w} \\
\text { randomisa }\end{array}$ & $\begin{array}{l}\text { eks post- } \\
\text { ion }\end{array}$ & \\
\hline $\begin{array}{l}\text { Participant qualitative palliative care nurse end of } \\
\text { trial interviews }\end{array}$ & Trial researcher ${ }^{*}$ & & End of tria & & \\
\hline
\end{tabular}

${ }^{*}$ Conducted through a different trial researcher involved in patient-completed questionnaire follow-up and clinical follow-up.

BPI, Brief Pain Inventory; EORTC, European Organization for Research and Treatment of Cancer; GP, general practitioner.

Health service delivery data

For all participating sites, the central research team will collect details of current service provision to help understand the local services and standard care pathways for the study population. This will include data collection to explore who is responsible for identifying patients as requiring pain management support and/or a referral to palliative care, who is responsible for performing referrals and how closely the oncology (or related) clinic staff work with their hospital and local community palliative care teams. 


\section{Sample size}

To address the potential effectiveness of the intervention the power calculation is based on the difference in mean pain severity (BPI) at 12 weeks. With $80 \%$ power and a two-sided type I error rate of 0.05 , we estimate that 128 patients (64 per group) will be required to detect a moderate intervention effect size of $0.5^{29}$ between the intervention and control arm. In addition, a relative reduction of $\geq 30 \%$ in pain severity (BPI) is an accepted threshold for clinically significant improvement in pain trials. ${ }^{30}$ Results from a previous study involving automated symptom modelling found a $27 \%$ difference in such improvement rates at 12 weeks. ${ }^{25}$ Our estimated sample size will therefore also provide $80 \%$ power to detect a similar difference in rate. As our patient sample is drawn from a generally frail population, we have allowed for an attrition rate of $20 \%$ and therefore aim to recruit 160 participants (80 per group). The trial is expected to recruit from four to five participating centres that will be selected due to their large oncology (or related) clinics.

\section{Data analysis}

There are no planned interim analyses; outcome data will be analysed once only. All analyses will be conducted on the intent-to-treat population, in which all participants will be included in the analysis according to allocation, regardless of non-compliance with the intervention. An overall two-sided $5 \%$ significance level will be used for all statistical endpoint comparisons. Details of all analysis are provided in box 1 .

\section{PATIENT AND PUBLIC INVOLVEMENT}

The IMPACCT research programme comprises four work streams. The first three work streams, running in parallel, sought to understand and improve current cancer pain management at the levels of the patient and their caregiver, health professional and healthcare system. Across these three work streams, extensive user engagement with patients, caregivers and health professionals occurred, informing an understanding of their priorities, experience and preferences relating to cancer pain management. Part of this work involved the development and piloting of interventions used in the trial, including assessment of their acceptability, and informed the design of the trial, its research question and outcome measures. The research programme also has a patient and public involvement (PPI) group, comprising patients with cancer and caregivers of those with cancer. PPI representatives are co-investigators on the research programme, contributors at all quarterly programme management meetings and members of the trial steering group. The latter enabled PPI representatives to inform the recruitment processes and conduct of the trial. For example, it was decided that due to participants having advanced disease, information sheets should provide contact details to enquire about study findings rather than active dissemination by the research team. PPI involvement has been
Box 1 Data analysis plan for primary and secondary outcomes, health economic analysis and qualitative data

\section{Analysis activities}

Primary outcomes

- To assess the primary implementation outcome, the proportion of participants receiving each intervention, at least one intervention and all interventions will be summarised overall and by recruiting site along with $95 \%$ Cls.

- To assess the primary effectiveness outcome, pain severity (Brief Pain Inventory, BPI), we will fit a linear mixed-effects regression model with repeated measures ( 6 and 12 weeks). The model will contain centre random effect, and fixed effects for intervention group, research centre, baseline score, time, and intervention group by time interaction. Similarly, a logistic mixed-effects regression model will be used to assess the proportion of participants with $\geq 30 \%$ reduction in pain severity.

\section{Secondary outcomes}

- The secondary outcomes BPI interference, participant's pain knowledge and experience, EQ-5D and European Organization for Research and Treatment of Cancer (EORTC) QLQ-C30 will be assessed using a linear mixed-effects regression model with repeated measures as per the primary outcome.

- The 7-point global rating of change in pain, healthcare use and safety data will be summarised.

- Exploratory subgroup analysis will be conducted, differentiating participants in the intervention arm who were engaged in the use of PainCheck versus those who were not. Descriptive statistics will be used to present the primary outcome at each time point for each subgroup.

Missing data

- Reasons for attrition and missing data will be summarised along with reason, following the classification set out in the MORECare statement ${ }^{43}$ : attrition due to death, illness or at random; with additional reason due to participant withdrawal.

- The pattern of missing data according to participant characteristics will be investigated to inform the multiple imputation approach and the assumptions of Missing At Random and Missing Not At Random.

- Regression analysis will handle missing data due to attrition by testing results from different methods of imputation, including multiple imputation ${ }^{44}$ in the primary analysis, allowing all participants in the intention-to-treat population to be included, and analysis to the availability of data in sensitivity analysis. This will allow us to test the trial conclusions under different assumptions and biases introduced through missing data.

\section{Health economic analysis}

- The economic evaluation will follow the National Institute for Health and Care Excellence reference case ${ }^{45}$ and hence will be a cost-utility analysis presenting cost per incremental quality-adjusted life year (QALY) from the perspective of the healthcare and personal social services provider. It will be informed by earlier work of the research team. ${ }^{46}$

- The evaluation will combine trial-based and model-based analyses. Trial data will be analysed to yield within-trial cost-utility results. Participants will complete the utility measures (EQ-5D and EORTC$8 \mathrm{D}$, the latter derived from the QLQ-C30) ${ }^{47}$ at baseline and follow-up along with a resource use questionnaire. The EQ-5D values will be used in the primary analysis with supplementary analyses presented based on the EORTC-8D and pain rating item from the BPI. Survival data will be combined with utility data to calculate QALYS and resource use costed using national resources (eg, National

Continued 


\section{Box 1 Continued}

Health Service reference costs, personal social services research unit costs). The development and implementation of the interventions will be costed following consultation with the trial researchers leading each Improving the Management of Pain from Advanced Cancer in the Community programme work stream. The within-trial analysis will present (where appropriate) incremental cost-effectiveness ratios (ICERs) for the interventions versus usual care with ICERs below $£ 20000$ usually indicative of cost-effectiveness. Nonparametric bootstrapping and deterministic sensitivity analyses will be conducted to estimate the level of uncertainty around the ICERs.

- In parallel, a simple decision-analytic Markov model will be developed. This will be developed according to best practice ${ }^{48}$ and yield cost per QALY estimates. The model will allow the extrapolation of expected costs and benefits beyond the trial period. It will also allow a more in-depth exploration of uncertainty in the ICERs and a more flexible exploration of scenario sensitivity analyses.

\section{Process evaluation}

- Quantitative analysis will summarise delivery and implementation of the intervention according to:

- Palliative care nurse use of interventions, including the number of participants seen by each palliative care nurse by trial arm to explore the level of clustering and potential for contamination by the nurse.

Training and supervision for intervention delivery.

- Participant uptake, including a flow diagram to depict uptake and usage according to the initial palliative care visit and subsequent use of PainCheck.

- Qualitative interview analysis: Interview transcripts will be analysed using framework analysis ${ }^{49}$ to draw out key themes from the data. The framework analysis process involves five key stages: (1) Familiarisation - getting an overview of the issues raised during the interviews; (2) Identifying a thematic framework - making notes on the key issues discussed; (3) Indexing-applying the thematic framework to the data; (4) Charting - moving data from individual interviews and putting sections into the framework; (5) Mapping and interpretation-the researcher attempts to make sense of the data and interpret the key themes and issues discussed.

central to all research programme activities, informing our approach to patient, caregiver and health professional engagement prior to and during the trial.

\section{DISCUSSION}

This trial will conclude a 5-year programme of research funded by the NIHR PGfAR Programme. The wider aim of the programme, IMPACCT, is to reduce distress from cancer pain in palliative care patients and reduce the impact on the NHS of avoidable admissions for cancer pain. We believe that our RCT has the potential to significantly influence NHS service delivery to community-based patients with pain from advanced cancer. We aim to provide definitive evidence of whether two simple interventions delivered by community palliative care nurse in palliative care that support self-management are clinically and cost-effective additions to standard community palliative care. We are conducting a detailed process evaluation that will inform an implementation strategy for the wider NHS if we find a benefit for intervention. One of our interventions, 'Tackling Cancer Pain-A toolkit for patients and families' addresses all the information recommendations in the National Institute for Health and Care Excellence guidance on 'Opioids in Palliative Care' and was runner-up in the British Medical Association Patient Education awards 2016. Our electronic pain monitoring system 'PainCheck' is underpinned by significant development work, ${ }^{31-35}$ which explores engagement by patient and healthcare professionals. PainCheck offers a potentially time-efficient and cost-efficient way for busy community palliative care teams to monitor patients with cancer pain and respond when needed.

\section{Ethics and dissemination}

A favourable ethical opinion was obtained from the NHS National Research Ethics Service Committee Yorkshire \& The Humber-Leeds East, reference number 15/YH/0235. The trial opened and recruited the first participant in October 2015. Screening, recruitment and implementation were monitored on a monthly basis. After 6 months of recruitment and after 13 patients had been recruited, it was apparent that the trial design needed to be changed to ensure the trial is embedded in existing NHS care pathways. A substantial amendment was made to remove the concept of 'early screening and referral' to allow identification at point of referral. The rationale for this was that patients were already being referred to community palliative care services for pain management support when needed. The trial is sponsored by the University of Leeds (Faculty Head of Research and Innovation Support, Faculty of Medicine and Health Research Office, University of Leeds), managed by the Clinical Trials Research Unit at the University of Leeds and supported by a Trial Management Group (TMG) and Trial Steering Committee (TSC). The TMG is composed of individuals responsible for the day-to-day management of the trial, including the PI (MIB), statisticians, trial manager, research nurse and researchers. The TSC includes external experts who will provide overall supervision for a trial on behalf of the Trial Sponsor and Trial Funder.

The following organisations have given research governance approval for the trial: Diana Princess of Wales Hospital, Grimsby; Care Plus Group, Grimsby; Nottingham City Hospital, Nottingham; Nottingham Citycare, Nottingham; St James University Hospital, Leeds; St Gemma's Hospice, Leeds; Wheatfields Hospice, Leeds; Wakefield Hospice, Wakefield; York Hospital, York; St Leonards Hospice, York; Bradford Royal Infirmary, Bradford; Marie Curie Hospice, Bradford; Huddersfield Royal Infirmary, Huddersfield; Kirkwood Hospice, Huddersfield; Churchill Hospital, Oxford; Sobell House, Oxford; Scarborough General Hospital, Scarborough; St Catherine's Hospice, Scarborough.

Data will be collected and retained in accordance with the Data Protection Act 1998 (and successor legislation). Trial documents (paper and electronic) will be retained in a secure location for 5 years after trial completion. To support dissemination of our findings, we will work 
with local and national patient advocacy groups (linking to public and patient involvement co-applicants on the wider programme) to explain our work and encourage wider adoption of our findings. We will also disseminate through academic papers and presentation at national and international clinical meetings.

\section{Author affiliations}

${ }^{1}$ Academic Unit of Palliative Care, Leeds Institute of Health Sciences, University of Leeds, Leeds, UK

${ }^{2}$ Clinical Trials Research Unit, Leeds Institute of Clinical Trials Research, University of Leeds, Leeds, UK

${ }^{3}$ Leeds Community Healthcare NHS Trust, Leeds, UK

${ }^{4}$ Division of Psychological and Social Medicine, Leeds Institute of Health Sciences, University of Leeds, Leeds, UK

${ }^{5}$ Academic Unit of Health Economics, Leeds Institute of Health Sciences, University of Leeds, Leeds, UK

${ }^{6}$ School of Healthcare, Baines Wing, University of Leeds, Leeds, UK

${ }^{7}$ Department of Health Sciences, University of York, Heslington, UK

Acknowledgements We thank our patient and public involvement representatives for their contribution throughout all stages of the research programme. We also thank members of the trial steering committee (Dr Barry Laird, Dr Wei Gao, Dr Sheila E Fisher) and the wider programme management group (Professor Alison Blenkinsopp, Mary Godfrey, Professor Robbie Foy, Professor Sue Pavitt, Dr Geoff Hall, Professor Richard Jones, Christine Allmark, Peter Rainey, Zoe Edwards, and Karen Vinall-Collier)

Contributors MJA, AWH and MF drafted the initial manuscript. All authors reviewed the manuscript prior to submission. All authors were involved in the critical revision of the article for important intellectual content and provided final approval of its content. The team comprises the primary investigator (MIB) and co-investigators (LEZ, BMB, SJC, CH, KF, JMB) of the larger research programme. The team includes a trial statistician (AWH), trial coordinator (MF), trial management lead (SH), health economists (DM, JOD) and lead research nurse (KB). Members of the research team also led the design, development and evaluation of the patient self-management educational intervention (JH, NDH, KF) and the eHealth intervention for routine pain assessment and monitoring in patients with advanced cancer (BMB, MJA, ST, JH).

Funding This article presents independent research funded by the National Institute for Health Research (NIHR) Programme Grant (RP-PG-0610-10114).

Disclaimer The views expressed are those of the author(s) and not necessarily those of the NHS, the NIHR or the Department of Health. The sponsor and funders had no involvement in the study design; collection, management, analysis and interpretation of data; writing of the report; and the decision to submit the report for publication.

Competing interests None declared.

Patient consent Detail has been removed from this case description/these case descriptions to ensure anonymity. The editors and reviewers have seen the detailed information available and are satisfied that the information backs up the case the authors are making.

Ethics approval Ethical approval was obtained from the Yorkshire \& The Humber—Leeds East Research Ethics Committee (reference: 15/YH/0235).

Provenance and peer review Not commissioned; peer reviewed for ethical and funding approval prior to submission.

Data sharing statement № additional data available.

Author note Trial registration number: ISRCTN18281271. The trial was added to the ISRCTN registry on 30 September 2015.

Open Access This is an Open Access article distributed in accordance with the Creative Commons Attribution Non Commercial (CC BY-NC 4.0) license, which permits others to distribute, remix, adapt, build upon this work non-commercially, and license their derivative works on different terms, provided the original work is properly cited and the use is non-commercial. See: http://creativecommons.org/ licenses/by-nc/4.0/

(c) Article author(s) (or their employer(s) unless otherwise stated in the text of the article) 2018. All rights reserved. No commercial use is permitted unless otherwise expressly granted.

\section{REFERENCES}

1. Macmillan Cancer Support. Statistics fact sheet. London: Macmillan Cancer Support, 2017. https://www.macmillan.org.uk/_images/ cancer-statistics-factsheet_tcm9-260514.pdf

2. van den Beuken-van Everdingen MH, de Rijke JM, Kessels AG, et al. Prevalence of pain in patients with cancer: a systematic review of the past 40 years. Ann Oncol 2007;18:1437-49.

3. Deandrea S, Corli O, Consonni D, et al. Prevalence of breakthrough cancer pain: a systematic review and a pooled analysis of published literature. J Pain Symptom Manage 2014;47:57-76.

4. Greco MT, Roberto A, Corli O, et al. Quality of cancer pain management: an update of a systematic review of undertreatment of patients with cancer. J Clin Oncol 2014;32:4149-54.

5. van den Beuken-van Everdingen MH, Hochstenbach LM, Joosten $\mathrm{EA}$, et al. Update on prevalence of pain in patients with cancer: systematic review and meta-analysis. J Pain Symptom Manage 2016;51:1070-90.

6. O'Leary MJ, O'Brien AC, Murphy M, et al. Place of care: from referral to specialist palliative care until death. BMJ Support Palliat Care 2017;7:53-9.

7. Kwon JH. Overcoming barriers in cancer pain management. J Clin Oncol 2014;32:1727-33.

8. Campbell V. The challenges of cancer pain assessment and management. Ulster Med J 2011;80:104-6.

9. British Medical Association. Improving analgesic use to support pain management at the end of life. London: British Medical Association, 2017.

10. Bakitas M, Lyons KD, Hegel MT, et al. The project ENABLE II randomized controlled trial to improve palliative care for rural patients with advanced cancer: baseline findings, methodological challenges, and solutions. Palliat Support Care 2009;7:75-86.

11. Brumley R, Enguidanos S, Jamison P, et al. Increased satisfaction with care and lower costs: results of a randomized trial of in-home palliative care. J Am Geriatr Soc 2007;55:993-1000.

12. Rabow MW, Dibble SL, Pantilat SZ, et al. The comprehensive care team: a controlled trial of outpatient palliative medicine consultation. Arch Intern Med 2004;164:83-91.

13. Temel JS, Greer JA, Muzikansky A, et al. Early palliative care for patients with metastatic non-small-cell lung cancer. N Engl J Med 2010;363:733-42.

14. Zimmermann C, Swami N, Krzyzanowska M, et al. Early palliative care for patients with advanced cancer: a cluster-randomised controlled trial. Lancet 2014;383:1721-30.

15. Hackett J, Godfrey M, Bennett MI. Patient and caregiver perspectives on managing pain in advanced cancer: a qualitative longitudinal study. Palliat Med 2016;30:711-9.

16. Valeberg BT, Miaskowski C, Hanestad BR, et al. Demographic, clinical, and pain characteristics are associated with average pain severity groups in a sample of oncology outpatients. J Pain 2008:9:873-82.

17. Reid CM, Gooberman-Hill R, Hanks GW. Opioid analgesics for cancer pain: symptom control for the living or comfort for the dying? A qualitative study to investigate the factors influencing the decision to accept morphine for pain caused by cancer. Ann Oncol 2008;19:44-8.

18. Lovell MR, Luckett T, Boyle FM, et al. Patient education, coaching, and self-management for cancer pain. J Clin Oncol 2014;32:1712-20.

19. Bennett MI, Bagnall AM, José Closs S. How effective are patientbased educational interventions in the management of cancer pain? Systematic review and meta-analysis. Pain 2009;143:192-9.

20. Cummings GG, Olivo SA, Biondo PD, et al. Effectiveness of knowledge translation interventions to improve cancer pain management. J Pain Symptom Manage 2011;41:915-39.

21. Sheinfeld Gorin S, Krebs P, Badr H, et al. Meta-analysis of psychosocial interventions to reduce pain in patients with cancer. $J$ Clin Oncol 2012;30:539-47.

22. Koller A, Miaskowski C, De Geest S, et al. A systematic evaluation of content, structure, and efficacy of interventions to improve patients' self-management of cancer pain. J Pain Symptom Manage 2012;44:264-84.

23. Trowbridge R, Dugan W, Jay SJ, et al. Determining the effectiveness of a clinical-practice intervention in improving the control of pain in outpatients with cancer. Acad Med 1997;72:798-800.

24. Kravitz RL, Delafield JP, Hays RD, et al. Bedside charting of pain levels in hospitalized patients with cancer: a randomized controlled trial. J Pain Symptom Manage 1996;11:81-7.

25. Kroenke K, Theobald D, Wu J, et al. Effect of telecare management on pain and depression in patients with cancer: a randomized trial. JAMA 2010;304:163-71. 
26. Oldenmenger WH, Sillevis Smitt PA, van Montfort CA, et al. A combined pain consultation and pain education program decreases average and current pain and decreases interference in daily life by pain in oncology outpatients: a randomized controlled trial. Pain 2011;152:2632-9.

27. Craig P, Dieppe P, Macintyre S, et al. Developing and evaluating complex interventions: the new Medical Research Council guidance. Int $J$ Nurs Stud 2013;50:587-92.

28. Kamper SJ, Maher CG, Mackay G. Global rating of change scales: a review of strengths and weaknesses and considerations for design. $J$ Man Manip Ther 2009;17:163-70.

29. Cohen J. Statistical power analysis for the behavioral sciences. 2nd Edn. Hillsdale, New Jersey: L Erlbaum, 1988.

30. Dworkin RH, Turk DC, Wyrwich KW, et al. Interpreting the clinical importance of treatment outcomes in chronic pain clinical trials: IMMPACT recommendations. J Pain 2008;9:105-21.

31. Taylor S, Allsop MJ, Shaw J, et al. The feasibility of collecting patient reported pain data using a system delivered across four modes of technology. Pain Med 2015;16:2212-3.

32. Allsop MJ, Taylor S, Bennett MI, et al. Understanding patient requirements for technology systems that support pain management in palliative care services: a qualitative study. Health Informatics $J$ 2017:14.

33. Taylor S, Allsop MJ, Bennett MI, et al. Usability testing of an electronic pain monitoring system for palliative cancer patients: a think-aloud study. Health Informatics J 2017:14.

34. Taylor S, Allsop MJ, Bekker HL, et al. Identifying professionals' needs in integrating electronic pain monitoring in community palliative care services: an interview study. Palliat Med 2017;31:661-70.

35. Allsop MJ, Taylor S, Mulvey MR, et al. Information and communication technology for managing pain in palliative care: a review of the literature. BMJ Support Palliat Care 2015;5:481-9.

36. Hughes ND, Closs SJ, Flemming K, et al. Supporting selfmanagement of pain by patients with advanced cancer: views of palliative care professionals. Support Care Cancer 2016;24:5049-57.

37. Flemming K, Closs SJ, Hughes ND, et al. Using qualitative research to overcome the shortcomings of systematic reviews when designing of a self-management intervention for advanced cancer pain. Int $J$ Qual Methods 2016;15:1-11.
38. Cleeland CS, Ryan KM. Pain assessment: global use of the brief pain inventory. Ann Acad Med Singapore 1994;23:129-38.

39. Rosenstiel AK, Keefe FJ. The use of coping strategies in chronic low back pain patients: relationship to patient characteristics and current adjustment. Pain 1983;17:33-44.

40. The City of Hope Pain \& Palliative Care Resource Center. The Patient Pain Questionnaire (PPQ). Measurement Instrument Database for the Social Science. www.midss.ie

41. Brooks R. EuroQol: the current state of play. Health Policy 1996;37:53-72.

42. Aaronson NK, Ahmedzai S, Bergman B, et al. The European Organization for Research and Treatment of Cancer QLQ-C30: a quality-of-life instrument for use in international clinical trials in oncology. J Natl Cancer Inst 1993;85:365-76.

43. Higginson IJ, Evans CJ, Grande G, et al. Evaluating complex interventions in end of life care: the MORECare statement on good practice generated by a synthesis of transparent expert consultations and systematic reviews. BMC Med 2013;11:11.

44. Rubin D. Multiple imputation for nonresponse in surveys. New York: John Wiley, 1987.

45. National Institute for Health and Care Excellence. Guide to the methods of technology appraisal 2013: process and methods (PMG9). 2013. https://www.nice.org.uk/process/pmg9/chapter/ foreword

46. Meads DM, O'Dwyer JL, Hulme CT, et al. Patient preferences for pain management in advanced cancer: results from a discrete choice experiment. Patient 2017;10:643-51.

47. Rowen D, Brazier J, Young T, et al. Deriving a preference-based measure for cancer using the EORTC QLQ-C30. Value Health 2011;14:721-31.

48. Caro JJ, Briggs AH, Siebert U, et al. Modeling good research practices - overview: a report of the ISPOR-SMDM Modeling Good Research Practices Task Force-1. Med Decis Making 2012;32:667-77.

49. Ritchie J, Spencer L. Analysing qualitative data, in qualitative data analysis for applied policy research. In: Bryman A, Bryman A, Burgess RG, eds. London: Routledge, 1994:173-94. 